\title{
Egg activation in physiological polyspermy
}

\author{
Yasuhiro Iwao \\ Laboratory of Molecular Developmental Biology, Department of Applied Molecular Biosciences, Graduate School of \\ Medicine, Yamaguchi University, 753-8512 Yamaguchi, Japan
}

Correspondence should be addressed to Y Iwao; Email: iwao@yamaguchi-u.ac.jp

\begin{abstract}
Fertilization is indispensable not only for restoring diploid genomes but also for the initiation of early embryonic cell cycles in sexual reproduction. While most animals exhibit monospermy, which is ensured by polyspermy blocks to prevent the entry of extra sperm into the egg at fertilization, several animals exhibit physiological polyspermy, in which the entry of several sperm is permitted but only one sperm nucleus participates in the formation of a zygote nucleus. Polyspermy requires that the sperm transmit the egg activation signal more slowly, thus allowing the egg to accept several sperm. An increase in intracellular $\mathrm{Ca}^{2+}$ concentration induced by the fertilizing sperm is both necessary and sufficient for egg activation in polyspermy. Multiple small $\mathrm{Ca}^{2+}$ waves induced by several fertilizing sperm result in a long-lasting $\mathrm{Ca}^{2+}$ rise, which is a characteristic of polyspermic amphibian eggs. We introduced a novel soluble sperm factor for egg activation, sperm-specific citrate synthase, into polyspermic newt eggs to cause $\mathrm{Ca}^{2+}$ waves. Citrate synthase may perform dual functions: as an enzyme in mitochondria and as $\mathrm{a} \mathrm{Ca}^{2+}$-inducing factor in egg cytoplasm. We also discuss the close relationship between the mode of fertilization and the $\mathrm{Ca}^{2+}$ rise at egg activation and consider changes in this process through evolution in vertebrates.

Reproduction (2012) 144 11-22
\end{abstract}

\section{Introduction}

Fertilization is essential for sexual reproduction in both animals and plants. It gives rise to several reactions important for embryonic development: mixing of the male and female genomes to restore diploid configuration, initiation of rapid cell cycles for early embryonic development, and activation of the synthesis of substances necessary for future morphogenesis. In this context, a haploid egg nucleus must fuse to a single haploid sperm nucleus to avoid syngamy with multiple sperm nuclei, which may lead to aneuploidy and arrested development (Elinson 1986, Iwao 2000a, Wong \& Wessel 2006). Most animals exhibit monospermy in which several blocks to polyspermy prevent extra sperm from entering the egg before sperm-egg fusion. First, the number of sperm reaching the egg surface is reduced during passage through egg investments, jelly layers, and vitelline envelopes or through the female reproductive tracts, uterus, and oviducts. Although the probability of multiple sperm entries decreases at fertilization, the eggs are still at risk from polyspermy. Soon after the entry of the first sperm into the egg, the egg's plasma membrane quickly changes to initiate a fast block to polyspermy by, for example, eliciting a positive-going fertilization potential to prevent fusion of a second sperm (Elinson 1986, Iwao 2000a, Wong \& Wessel 2006). The egg investments contribute by delaying the arrival of the second sperm, which helps the egg prepare the block to polyspermy. After the temporal fast block, permanent blocks are achieved by, for example, the formation of a fertilization envelope mediated by exocytosis of cortical granules to prevent sperm penetration completely. Although the structures and the molecules involved in these polyspermy blocks vary among animal species (Wong \& Wessel 2006), each is accomplished by eggs that can prevent the entry of extra sperm before their fusion with the egg membrane. However, in each case, the egg must detect the arrival and entry of the first sperm through its membrane and then undergo activation to rapidly initiate block mechanisms against polyspermy. The fertilizing sperm must provide an activation signal in the egg cytoplasm, which rapidly propagates through the entire egg cytoplasm.

Interestingly, there are some species in both invertebrates and vertebrates whose eggs normally accept more than one sperm in the egg cytoplasm at fertilization: physiological polyspermy has been observed in ctenophora, elasmobranchs, urodele amphibians, reptiles, and birds (Elinson 1986, Iwao 2000a, Wong \& Wessel 2006, Snook et al. 2011). In contrast to those of monospermic species, physiologically polyspermic eggs produce no block to polyspermy before the membrane fusion with extra sperm, although the number of sperm reaching the eggs may be limited by jelly layers in urodeles or oviducts in birds (Iwao 2000a,b, Wong \& Wessel 2006). As slower 
egg activation may allow the entry of several sperm in polyspermic species, their signals for egg activation may be different from those in monospermic species. However, it should be noted that even in these polyspermic eggs, only one sperm nucleus is ultimately allowed to contact the egg nucleus at syngamy to form a diploid zygote nucleus, while the other sperm nuclei undergo degeneration, thus ensuring embryonic development with a diploid configuration.

An analysis of the molecular mechanisms of egg activation in amphibians, as well as the mode of fertilization, may provide insights into the evolution of vertebrate fertilization systems. Most anurans, frogs and toads, exhibit monospermy, while most urodeles, newts and salamanders, exhibit physiological polyspermy. In addition, the monospermic salamander, Hynobius nebulosus (Iwao 1989), as well as the occasionally polyspermic frog, Discoglossus pictus (Talevi 1989), exhibits intermediate characteristics that may help to elucidate the evolution of egg activation in the physiological polyspermy of vertebrates. Comparing egg activation mechanisms in physiological polyspermic eggs and monospermic species reveals that polyspermic eggs display unique fertilization $\mathrm{Ca}^{2+}$ signals that are very different to monospermic species. Such different fertilization $\mathrm{Ca}^{2+}$ signals seem to be mediated by a new type of sperm factor that is different from mammalian or monospermic amphibian species. Here, we analyze egg activation in physiological polyspermic species and compare it with that in monospermic species, with particular interest in the $\mathrm{Ca}^{2+}$ rise at fertilization and in a novel sperm factor for egg activation, citrate synthase, in polyspermic urodeles. In addition, such variations in the mechanisms responsible for sperm-triggered $\mathrm{Ca}^{2+}$ increases among amphibians raise questions on how the transition between monospermy and polyspermy might have occurred during vertebrate evolution. We also discuss the variation in the mode of fertilization and the $\mathrm{Ca}^{2+}$ rise at egg activation as a means of tracing the transition between monospermy and polyspermy during vertebrate evolution.

\section{Egg activation responses at physiological polyspermy $\mathrm{Ca}^{2+}$ rises during fertilization}

In both amniote and anamniote vertebrates, physiological polyspermy is found in species with internal fertilization and yolky eggs, such as cartilaginous fishes, urodele amphibians, reptiles, and birds (Elinson 1986, Iwao 2000a, Wong \& Wessel 2006, Snook et al. 2011). Fertilizing sperm must provide a signal to trigger the initiation of development, i.e. egg activation. An increase in free $\mathrm{Ca}^{2+}$ concentration in the egg cytoplasm $\left(\left[\mathrm{Ca}^{2+}\right]_{\mathrm{i}}\right)$ induced by the fertilizing sperm is the most important factor for egg activation in both monospermic and physiologically polyspermic species (Fig. 1;
Whitaker 2006). In the monospermic frog, Xenopus laevis, a transient and large increase in $\left[\mathrm{Ca}^{2+}\right]_{i}$ induced by a single sperm spread into the entire egg cytoplasm as a $\mathrm{Ca}^{2+}$ wave (Fig. 1A and D; Nuccitelli et al. 1993, Fontanilla \& Nuccitelli 1998), whereas a slow rise in $\left[\mathrm{Ca}^{2+}\right]_{i}$ is reported in the polyspermy of the newt, Cynops pyrrhogaster, as detected by $\mathrm{Ca}^{2+}$-sensitive photoprotein (Yoshimoto \& Hiramoto 1991, Yamamoto et al. 1999) and a locally propagative change in $\left[\mathrm{Ca}^{2+}\right]_{i}$ was observed by a $\mathrm{Ca}^{2+}$-sensitive electrode in Pleurodeles waltl (Grandin \& Charbonneau 1992). The detailed changes in $\left[\mathrm{Ca}^{2+}\right]_{i}$ at polyspermy have been investigated in Cynops eggs by a $\mathrm{Ca}^{2+}$-sensitive fluorescence dye (Harada et al. 2011). An initial $\mathrm{Ca}^{2+}$ rise at a sperm entry site propagates as a $\mathrm{Ca}^{2+}$ wave in the egg cytoplasm (Fig. 1B). The peak level of the $\mathrm{Ca}^{2+}$ rise is estimated to be $0.15 \mu \mathrm{M}$ in Pleurodeles (Grandin \& Charbonneau 1992). Although the precise level of $\left[\mathrm{Ca}^{2+}\right]_{i}$ has yet to be determined in Cynops eggs, the peak level is much lower than that in Xenopus eggs: about $1.2 \mu \mathrm{M}$ in the cortex (Fontanilla \& Nuccitelli 1998). The $\mathrm{Ca}^{2+}$ wave at Cynops fertilization, in some cases, is preceded by an initial spike-like $\mathrm{Ca}^{2+}$ rise (Fig. 1E). Each $\mathrm{Ca}^{2+}$ wave initiated from the sperm entry site spreads in the egg cytoplasm but does not reach the opposite side of the egg. The observed velocity of $5.1 \mu \mathrm{m} / \mathrm{s}$ for the $\mathrm{Ca}^{2+}$ wave in Cynops eggs is slightly slower than that observed in the cortex of Xenopus eggs $(8.9 \mu \mathrm{m} / \mathrm{s})$ but similar to that in the center $(5.7 \mu \mathrm{m} / \mathrm{s}$; Fontanilla \& Nuccitelli 1998). The slower $\mathrm{Ca}^{2+}$ waves are probably due to a lack of endoplasmic reticulum (ER) as intracellular $\mathrm{Ca}^{2+}$ stores in the cortex of the Cynops eggs (Fig. 2; Harada et al. 2011). The $\mathrm{Ca}^{2+}$ wave induced by a single sperm propagates in one-eighth to one-quarter of the egg surface and multiple $\mathrm{Ca}^{2+}$ waves occur 10-15 min after the first sperm entry. The relatively high $\left[\mathrm{Ca}^{2+}\right]_{i}$ is maintained for 30-40 min after fertilization. Thus, several sperm must enter to increase $\left[\mathrm{Ca}^{2+}\right]_{i}$ over the entire egg. Usually, 2-20 sperm enter a Cynops egg and then initiate egg activation (Iwao et al. $1985,1993)$. The multiple $\mathrm{Ca}^{2+}$ waves induced by all fertilizing sperm are probably necessary for complete activation of physiologically polyspermic eggs. In the polyspermy of the frog, Discoglossus, an increase in $\left[\mathrm{Ca}^{2+}\right]_{\mathrm{i}}(0.4-1.3 \mu \mathrm{M})$ lasts for $50 \mathrm{~min}$ after fertilization, and a $\mathrm{Ca}^{2+}$ wave probably propagates toward the entire egg cortex from the sperm entry sites restricted in an animal dimple (Nuccitelli et al. 1988). Several spike-like depolarizations in response to each sperm entry are, however, preceded before a long-lasting depolarization mediated by the opening of $\mathrm{Ca}^{2+}$-activated $\mathrm{Cl}^{-}$ channels, as described below (Talevi 1989). This suggests that a nonpropagative small $\mathrm{Ca}^{2+}$ rise induced by each sperm entry occurs in advance of the major $\mathrm{Ca}^{2+}$ wave. The changes in $\left[\mathrm{Ca}^{2+}\right]_{i}$ at fertilization of other polyspermic species remain unknown. 
(A) Monospermic frog egg (single $\mathrm{Ca}^{2+}$ wave)

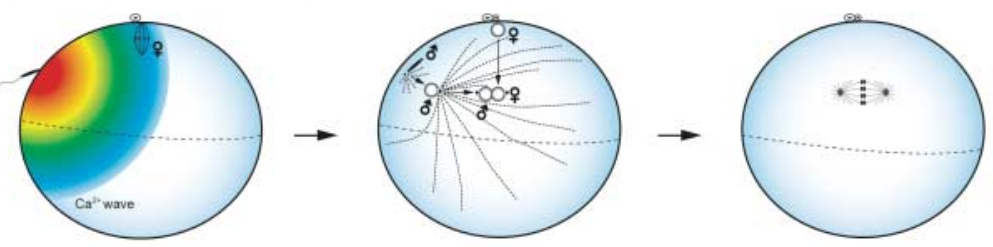

(B) Polyspermic newt egg (multiple $\mathrm{Ca}^{2+}$ waves)

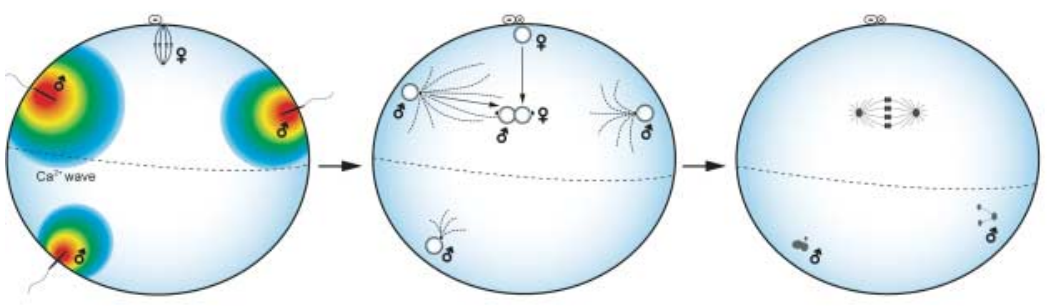

(C) Monospermic mouse egg ( $\mathrm{Ca}^{2+}$ oscillations)

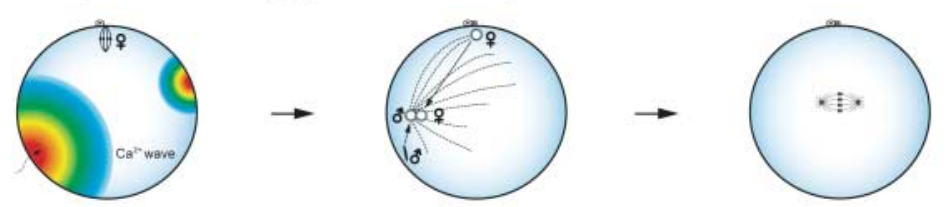

(D) Monospermic frog egg (single $\mathrm{Ca}^{2 *}$ wave)

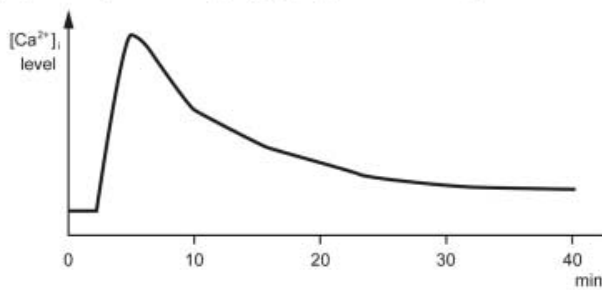

(E) Polyspermic newt egg (multiple $\mathrm{Ca}^{2+}$ waves)

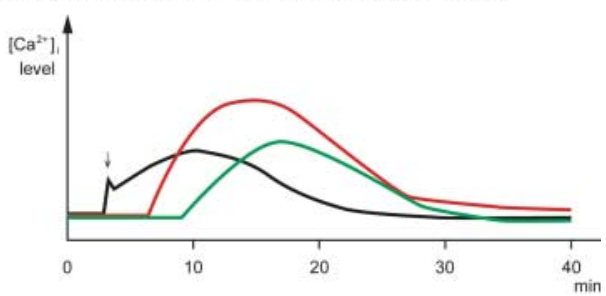

(F) Monospermic mouse egg ( $\mathrm{Ca}^{2+}$ oscillations)

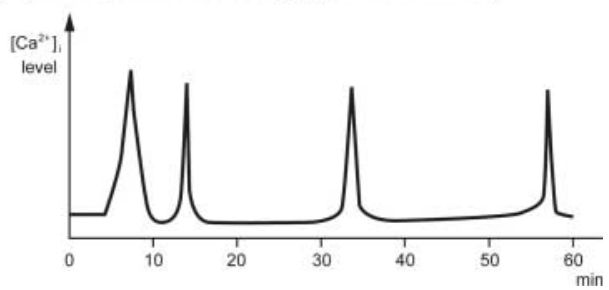

Figure $1 \mathrm{Ca}^{2+}$ rises and formation of zygote nucleus in vertebrate eggs. (A) A Ca ${ }^{2+}$ wave in an egg of the monospermic frog, Xenopus, spreading in the entire egg cytoplasm from the entry site of a single sperm. The transient $\mathrm{Ca}^{2+}$ increase peaks $1-3$ min after fertilization and continued for about $15 \mathrm{~min}$ (D). The sperm pronucleus develops a large aster and makes contact with an egg pronucleus to form a zygote nucleus. (B) Multiple Ca ${ }^{2+}$ waves in an egg of the polyspermic newt, Cynops, showing each $\mathrm{Ca}^{2+}$ wave propagating in about one-eighth to one-quarter of the egg cytoplasm. Some $\mathrm{Ca}^{2+}$ waves are preceded by a spike-like increase (arrow). As each $\mathrm{Ca}^{2+}$ wave propagates for about $15-20$ min, the total $\mathrm{Ca}^{2+}$ rise continues for about $40 \mathrm{~min}$ (E). The sperm pronucleus in the animal hemisphere develops larger asters and the nucleus nearest to the egg pronucleus likely makes contact with it to form a zygote nucleus. Other accessory sperm pronuclei undergo degeneration without participating in cell division. (C) $\mathrm{Ca}^{2+}$ oscillations in a monospermic mouse egg. The first $\mathrm{Ca}^{2+}$ wave is induced at the sperm entry site followed by repetitive Ca ${ }^{2+}$ waves. The $\mathrm{Ca}^{2+}$ rises continue every $10-15 \mathrm{~min}$ for $2 \mathrm{~h}$ after fertilization (F). The sperm pronucleus develops an aster to form a zygote nucleus with an egg pronucleus.

\section{Mechanisms of sperm-triggered $\mathrm{Ca}^{2+}$ release in polyspermic eggs}

The rise in $\left[\mathrm{Ca}^{2+}\right]_{i}$ induced by the fertilizing sperm is both necessary and sufficient for egg activation in physiologically polyspermic urodeles. Prevention of the $\mathrm{Ca}^{2+}$ rise at fertilization by a $\mathrm{Ca}^{2+}$ chelator inhibits resumption of meiosis (Yamamoto et al. 1999), and an artificial increase in $\left[\mathrm{Ca}^{2+}\right]_{i}$ from intracellular $\mathrm{Ca}^{2+}$ stores caused egg activation (Charbonneau \& Picheral 1983, Iwao \& Masui 1995, Yamamoto et al. 1999). Although the eggs of both monospermic frogs and the monospermic Hynobius salamander are activated by pricking with a fine needle to bring about a small $\mathrm{Ca}^{2+}$ influx, the eggs of most polyspermic urodeles, except for Pleurodeles (Aimar \& Labrousse 1975), are insensitive to pricking and less sensitive to a $\mathrm{Ca}^{2+}$ ionophore (Iwao \& Masui 1995, Iwao 2000b), corresponding to a lack of ER as a $\mathrm{Ca}^{2+}$-propagating system in the egg cortex of newt eggs. Inositol-1,4,5-trisphosphate $\left(\mathrm{IP}_{3}\right)$ receptors on the
ER are closely involved in the $\mathrm{Ca}^{2+}$ rises at polyspermy. Injection of $\mathrm{IP}_{3}$ into the eggs or the isolated egg cytoplasm induces a $\mathrm{Ca}^{2+}$ rise, and injection of heparin to inhibit $\mathrm{IP}_{3}$ receptors prevents $\mathrm{Ca}^{2+}$ waves at fertilization (Yamamoto et al. 2001, Harada et al. 2011). The expression of exogenous phospholipase $C$ (PLC) activates Cynops eggs with an accompanying $\mathrm{Ca}^{2+}$ rise (Harada et al. 2007). Thus, the $\mathrm{Ca}^{2+}$ waves in Cynops eggs are probably induced by the propagative $\mathrm{Ca}^{2+}$ release acting on $\mathrm{IP}_{3}$ receptors directly or through $\mathrm{IP}_{3}$ production (Fig. 2), but ryanodine receptors are unlikely to be involved in the $\mathrm{Ca}^{2+}$ rise (Yamamoto et al. 2001). However, the mechanism of $\mathrm{Ca}^{2+}$ rise is probably different from that in monospermic Xenopus eggs with a single $\mathrm{Ca}^{2+}$ wave propagating whole egg cytoplasm.

\section{Responses in egg activation}

The $\mathrm{Ca}^{2+}$ rise at fertilization causes egg activation, which is characterized by a series of morphological and 
(A) Monospermic frog egg

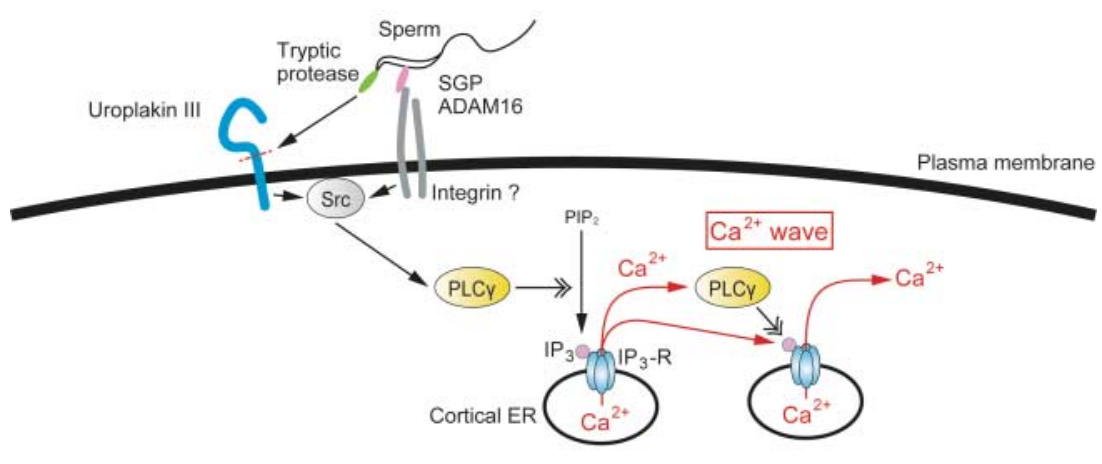

(B) Polyspermic newt egg

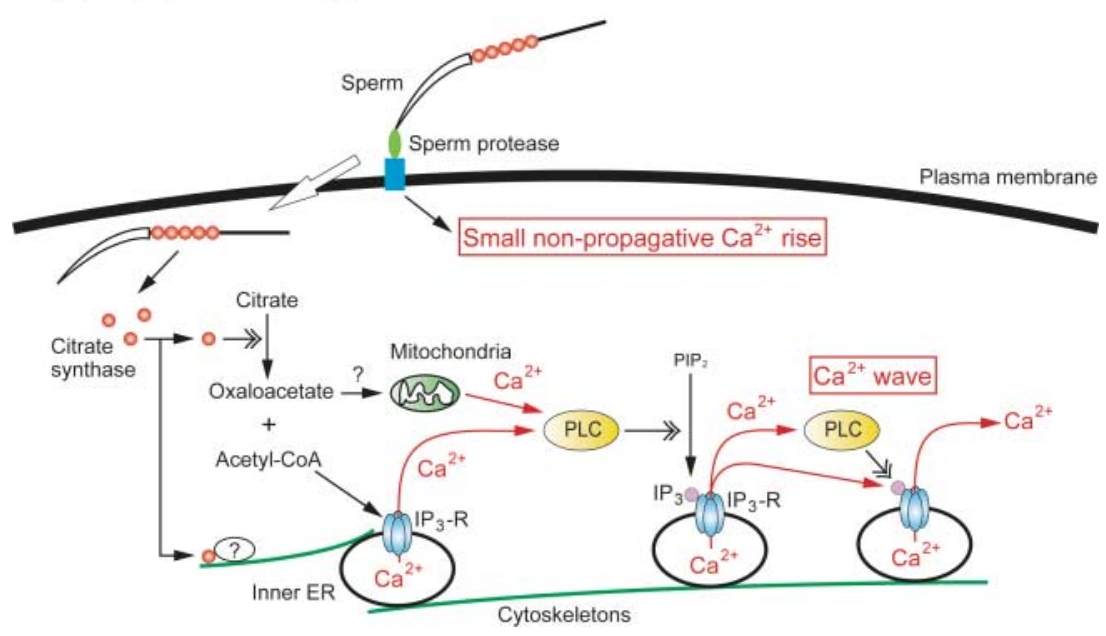

Figure 2 Schematic potential models of the signaling in egg activation of the monospermic frog, Xenopus (A), or of the polyspermic newt, Cynops (B). In Xenopus, the protease activity on the sperm, in association with sperm surface glycoprotein (SGP) and ADAM16, may cleave an egg receptor, Uroplakin III (UPIII), and then the activated Src kinase (Src) stimulates phospholipase $\mathrm{C}_{\gamma}(\mathrm{PLC} \gamma)$. Inositol 1,4,5-trisphosphate $\left(\mathrm{IP}_{3}\right)$ from phosphatidylinositol 4,5-bisphosphate (PIP2) induces a local $\mathrm{Ca}^{2+}$ increase in the egg cortex. The cortical $\mathrm{Ca}^{2+}$ increase seems to propagate through the cortical endoplasmic reticulum (ER), which is abundant in the Xenopus egg, as a $\mathrm{Ca}^{2+}$ wave. In Cynops, the sperm protease activity induces a small nonpropagative $\mathrm{Ca}^{2+}$ rise and then sperm-specific citrate synthase introduced from each sperm induces each $\mathrm{Ca}^{2+}$ wave. While the $\mathrm{Ca}^{2+}$ increase from the inner ER with cytoskeletons, or from mitochondria, may be caused by oxaloacetate, or by acetyl-CoA, respectively, another molecule in association with cytoskeletons may be involved in the course of $\mathrm{Ca}^{2+}$ rise induced by sperm citrate synthase. biochemical changes in the egg. In monospermic species, frogs, and Hynobius salamanders, the Ca rise opens $\mathrm{Ca}^{2+}$-activated $\mathrm{Cl}^{-}$channels on the egg plasma membrane to produce a rapid $(<1 \mathrm{~s})$ depolarization of the membrane and a positive-going fertilization potential, which prevents the entry of other sperm, as a fast block to polyspermy (Cross \& Elinson 1980, Iwao 1989, Iwao \& Jaffe 1989). In polyspermic urodeles, the eggs of Pleurodeles and Ambystoma mexicanum display no electrical responses to sperm entry (Charbonneau et al. 1983), but Cynops eggs elicit small hyperpolarizations probably mediated by $\mathrm{Na}^{+}$channels in response to each sperm entry (Iwao 1985). The polyspermic urodele eggs lack the ability to produce a positive-going fertilization potential, i.e. $\mathrm{Ca}^{2+}$-activated $\mathrm{Cl}^{-}$channels. In addition, the entry of Cynops sperm into the eggs is not affected by the positive membrane potential, indicating a lack of the fast electrical block to polyspermy on the egg plasma membrane (Iwao \& Jaffe 1989). On the other hand, polyspermic Discoglossus eggs elicit a positive-going fertilization potential mediated by $\mathrm{Cl}^{-}$channels (Talevi et al. 1985, Nuccitelli et al. 1988), but they do not block subsequent sperm entries, as sperm penetration is independent of the egg's membrane potential (Talevi 1989). Brief depolarizations occur in response to each sperm entry into the periphery of the dimple (Talevi \& Campanella 1988), indicating a small $\mathrm{Ca}^{2+}$ rise induced by each sperm entry, as described above. Although there have been few studies on the electrical responses in other polyspermic vertebrate species, in the polyspermy of the ctenophore, Beroe ovata, each sperm induces a $\mathrm{Na}^{+}$-dependent depolarization, lasting about $60 \mathrm{~s}$, preceded by an action potential (Goudeau \& Goudeau 1993), suggesting that there is no electrical regulation of sperm-egg fusion that prevents polyspermy.

Monospermic frog eggs undergo cortical granule exocytosis to transform the vitelline envelope into the fertilization envelope through which the extra sperm cannot penetrate (Hedrick 2008). The eggs of urodele amphibian, including the monospermic Hynobius (Iwao 1989), have no cortical granules, indicating the absence of a formed fertilization envelope. Cortical contraction, characterized by apparent movement of cortical pigments toward the animal pole, does not occur in response to the $\mathrm{Ca}^{2+}$ rise at newt egg activation, but small accumulations of cortical pigments at sperm entry sites are visible on the animal hemisphere (Iwao 2000a). The cell cycle of unfertilized newt eggs is arrested at the second meiotic metaphase with a high activity of 
M phase-promoting factor (MPF; cdc2 kinase (cdk1), and cyclin B) maintained by c-Mos (Iwao \& Masui 1995, Sakamoto et al. 1998, Vaur et al. 2004, Pelczar et al. 2007). The amount of cyclin B in the unfertilized egg is approximately one-fourth in cleaving eggs but is primarily distributed in the cortex of the animal hemisphere and chromosomes (Sakamoto et al. 1998, Iwao et al. 2002). Cyclin B as well as c-Mos disappeared soon after fertilization when the sperm asters expand through the egg cytoplasm (Yamamoto et al. 2001, Iwao et al. 2002, Pelczar et al. 2007) and then the activity of both cdc2 kinase and MAPK decreases (Iwao et al. 1993, Sakamoto et al. 1998, Pelczar et al. 2007). Degradation of MPF might occur downstream of the $\mathrm{Ca}^{2+}$ rises at fertilization through a calcineurin/CaMKII/APC cascade alike in Xenopus eggs (Nishiyama et al. 2007). Inhibition of protein synthesis causes resumption of meiosis in Cynops eggs (Iwao \& Masui 1995), indicating that inhibition of short-lived proteins such as cyclin B, for example, is involved in egg activation downstream of the $\mathrm{Ca}^{2+}$ rises. Following the emission of the second polar body at the animal pole, the fertilized egg undergo $\mathrm{S}$ phase of the first mitotic cell cycle.

\section{A cytoplasmic block to polyspermy in physiologically polyspermic eggs}

In previous studies on the physiological polyspermy of newt eggs, all incorporated sperm form sperm pronuclei concomitantly with spreading sperm asters from each sperm centriole (Fankhauser 1948, Iwao et al. 1985, 1993, 1997, 2002). Only one principal sperm pronucleus, probably nearest to the egg nucleus and with the largest sperm aster, makes contact with an egg pronucleus to form a zygote nucleus in the center of the animal hemisphere. The $\gamma$-tubulin predominantly distributed in the animal hemisphere is heavily concentrated in the centrosome in the principal sperm pronucleus to promote microtubule polymerization (Iwao et al. 2002). However, it remains unknown how the sperm pronucleus makes contact with the egg nucleus. Sperm pronuclei enter $S$ phase, but the progress in DNA synthesis is faster in the principal sperm pronucleus and the egg pronucleus than in the accessory sperm pronuclei (Wakimoto 1979, Iwao et al. 1993). The zygote nucleus, therefore, enters $M$ phase to form a bipolar spindle, earlier than the accessory sperm nuclei (Iwao \& Elinson 1990, Iwao et al. 1993, 2002). Separation of the centrosome never occurs in the accessory sperm nuclei that undergo degeneration (pycnosis) before the first cleavage. The failure of progress in the nuclear cycle and the subsequent nuclear degeneration are probably caused by insufficient exposure of MPF (cdc2 kinase) activity in the accessory sperm pronuclei in the periphery of the egg (Iwao \& Elinson 1990, Iwao et al. 2002). MPF activity in the animal hemisphere is higher than that in the vegetal hemisphere at $M$ phase (Iwao et al. 1993), and more active cdc2 kinase is localized in the animal hemisphere than in the vegetal hemisphere. Cyclin B1 is highly accumulated in the zygote nucleus but not in the accessory sperm nuclei (Iwao et al. 2002). The degeneration of both centrosomes and chromosomes in the accessory sperm nuclei appears to be caused through a process similar to that of apoptosis in somatic cells, but the molecular mechanisms remain to be investigated. Thus, a very slow block to polyspermy in egg cytoplasm is accomplished in physiologically polyspermic eggs.

In polyspermic bird eggs, accessory sperm nuclei enter into $M$ phase at the first cleavage but do not induce the extra cleavage furrow and undergo degeneration in the margin of a blastodisc (Harper 1904, Perry 1987, Waddington et al. 1998). In eggs of the polyspermic ctenophore, Beroe, a single sperm nucleus is selected to form the zygote nucleus in the egg cytoplasm (Carré \& Sardet 1984, Houliston et al. 1993, Rouvière et al. 1994). The molecular mechanisms for suppression of accessory sperm nuclei, however, remain unknown in those species.

\section{Mechanism of egg activation in physiological polyspermy \\ Comparison of the mechanisms of $\mathrm{Ca}^{2+}$ release in mono vs polyspermic eggs}

There must be a specific mechanism by which a fertilizing sperm transmits the initial signal for the $\mathrm{Ca}^{2+}$ rise at physiological polyspermy. As mentioned earlier, faster egg activation is probably characteristic of monospermic species, but not of physiologically polyspermic species, so that the mechanisms underlying egg activation must be different between those species. To elucidate this process, we compared the signaling mechanisms in egg activation between monospermic and polyspermic species in vertebrates. There are at least two major models to account for the $\left[\mathrm{Ca}^{2+}\right]_{i}$ increase at vertebrate fertilization (Fig. 2; Iwao 2000b, Nomikos et al. 2012). One is that a sperm binds to a receptor on the egg plasma membrane and then stimulates a signal transduction pathway causing the $\mathrm{Ca}^{2+}$ rise. Another is that a sperm introduces factors into the egg, such as $\mathrm{Ca}^{2+}, \mathrm{PLC}$, or other agents, that can induce the $\mathrm{Ca}^{2+}$ rise. In any case, a fertilizing sperm must stimulate a propagative $\left[\mathrm{Ca}^{2+}\right]_{i}$ increase in the egg cytoplasm to produce the $\mathrm{Ca}^{2+}$ wave.

In monospermic Xenopus eggs, $\mathrm{a} \mathrm{Ca}^{2+}$ rise is induced by external application of peptides containing RGD residues acting as ligands for integrins (Iwao \& Fujimura 1996) or peptides from the disintegrin domain of xMDC16 (Shilling et al. 1998). Protease activity against a peptide containing GRR residues also induces activation in Xenopus eggs (Iwao et al. 1994, Mizote et al. 1999). In Xenopus fertilization, a protein tyrosine 
kinase, Src kinase, localized in membrane microdomains (membrane rafts) of unfertilized eggs, is phosphorylated and then the activated Src kinase stimulates $\mathrm{IP}_{3}$ production through $\mathrm{PLC} \gamma$ (Fig. 2A; Sato et al. 1999, 2003). Sperm induces transient phosphorylation of Uroplakin III (UPIII) on the egg membrane dependent on Src kinase (Mahbub Hasan et al. 2005, 2007, Sakakibara et al. 2005). It has been postulated that the sperm protease associated with sperm surface glycoprotein (SGP, Nagai et al. 2009) cleaves UPIII to activate Src kinase. UPIII seems to serve as a primary sperm receptor for the $\mathrm{Ca}^{2+}$ release from cortical ER (Fig. 2A). In the monospermy of the primitive jawless fish lamprey, a positive-going fertilization potential blocks sperm-egg fusion, but not egg activation (Kobayashi et al. 1994), indicating the involvement of a receptor on the egg membrane in the signaling pathway for egg activation. Monospermic species without the fast polyspermy block, however, seem to possess a different system for egg activation. Bony fishes exhibit monospermy without the fast electrical block to polyspermy on the egg membrane (Nuccitelli 1980). Their monospermy is ensured by the micropyle on the chorion (vitelline envelope) to limit the number of sperm reaching the egg plasma membrane (Hart 1990, Iwamatsu 2000). Bony fish sperm contain a factor for activation of homologous eggs (Iwamatsu \& Ohta 1974) or for inducing a $\mathrm{Ca}^{2+}$ rise in mouse eggs or sea urchin egg homogenates (Coward et al.

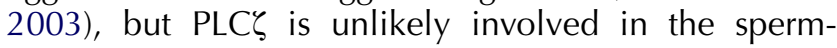
induced activation of fish eggs (Coward et al. 2011). Monospermic mammalian eggs also lack a fast electrical block to polyspermy (Jaffe et al. 1983, Gianaroli et al. 1994, Kline \& Stewart-Savage 1994). $\mathrm{Ca}^{2+}$ oscillations induced by sperm, however, appear to play a role in the slow membrane block to polyspermy in mammalian fertilization (Gardner et al. 2007). A soluble sperm factor for egg activation enters into the egg cytoplasm after sperm-egg fusion in mammals (Swann 1990, Parrington

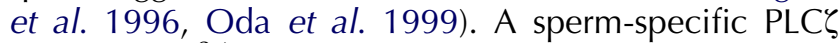
generates $\mathrm{Ca}^{2+}$ oscillation in mouse eggs (Fig. 1C and F; Saunders et al. 2002, Kouchi et al. 2004) and a single sperm contains sufficient PLC $\zeta$ protein to induce $\mathrm{Ca}^{2+}$ oscillation (Saunders et al. 2002, Yoda et al. 2004), indicating that the major active component for $\mathrm{Ca}^{2+}$ oscillations is PLC $\zeta$ in mammalian fertilization. Thus, the signal transduction for egg activation around the sperm binding to the egg membrane may play a role in the fast electrical block to polyspermy in monospermic species.

\section{Citrate synthase as a novel sperm factor for newt egg activation}

In polyspermic Cynops eggs, a small and nonpropagative $\mathrm{Ca}^{2+}$ rise is induced by the tryptic acrosomal protease (Harada et al. 2011), but only a small number of eggs are activated by treatment with the sperm protease (Iwao et al. 1994). The initial spike-like $\mathrm{Ca}^{2+}$ rise at Cynops fertilization seems to be induced by the sperm protease at the binding of the sperm on the egg surface but is insufficient for inducing the propagative $\mathrm{Ca}^{2+}$ wave necessary for egg activation (Fig. 2B). The injection of sperm soluble components, a sperm factor, into the egg causes a $\mathrm{Ca}^{2+}$ wave and egg activation (Yamamoto et al. 2001). The $\mathrm{Ca}^{2+}$ wave induced by the sperm factor has a velocity of $6.2 \mu \mathrm{m} / \mathrm{s}$, which is similar to those induced by the fertilizing sperm, and it triggers a complete activation, including resumption of meiosis, degradation of cyclin B and c-Mos, and DNA replication followed by abortive cleavage due to the lack of sperm centrioles. The sperm factor for egg activation is highly purified and characterized (Harada et al. 2007), which reveals that citrate synthase in the sperm cytoplasm induces the $\mathrm{Ca}^{2+}$ wave that causes the egg activation (Fig. 2B). The sperm lack sufficient PLC activity to induce egg activation because no $\mathrm{Ca}^{2+}$ rise occurs in Xenopus eggs by injection of the Cynops sperm extract. The sperm-specific citrate synthase $(45 \mathrm{kDa})$ is slightly heavier than those observed in heart tissue and in unfertilized eggs $(43 \mathrm{kDa})$. The $\mathrm{Ca}^{2+}$ rise is induced by the injection of not only porcine citrate synthase but also citrate synthase mRNA into unfertilized eggs (Harada et al. 2007). The egg-activating activity in the sperm extract was reduced by the treatment with anticitrate synthase antibody. Most citrate synthase is distributed as a fibrous structure from the neck to the middle piece outside the mitochondria. The sperm citrate synthase can be exposed to egg cytoplasm soon after sperm entry because all sperm components, including the middle piece and the tail, are incorporated into the egg (Picheral 1977, Iwao 2000a). It is unknown whether a single newt sperm can induce sufficient egg activation activity in the newt egg. In Cynops fertilization, 2-20 sperm enter an egg (Iwao et al. 1985, 1993), indicating that at least a double sperm entry is required for full activation. A sperm extract containing the cytoplasm equivalent of a single sperm is able to activate about $20 \%$ of the egg, corresponding well to the proportionately low level of citrate synthase (2 pg) and its enzymatic activity in a single sperm (Yamamoto et al. 2001, Harada et al. 2007, 2011). The multiple $\mathrm{Ca}^{2+}$ increases induced by all fertilizing sperm must be necessary for complete activation of polyspermic Cynops eggs. The lower level of egg activation activity induced by a single sperm will delay the initiation of egg activation until several sperm enter the same egg. Thus, the sperm-specific citrate synthase appears to represent a novel and major sperm factor for egg activation in physiologically polyspermic newt eggs.

\section{$\mathrm{ACa}^{2+}$ rise by citrate synthase}

It is important to understand the mechanism by which citrate synthase, derived from fertilizing sperm, can induce a $\mathrm{Ca}^{2+}$ rise in the egg cytoplasm. The ER containing $\mathrm{IP}_{3}$ receptor in unfertilized Cynops eggs has been observed to form large clusters, probably with 
cytoskeletons, in the inner egg cytoplasm (Fig. 2B; Harada et al. 2011). A local and spike-like $\mathrm{Ca}^{2+}$ rise is induced by each injection of the sperm extract into an isolated ER-rich fraction. Although adequate conformation of the ER must be necessary for the formation of $\mathrm{Ca}^{2+}$ waves, $\mathrm{Ca}^{2+}$ is mainly released from the ER rather than from mitochondria in response to sperm citrate synthase. The ability to induce multiple $\mathrm{Ca}^{2+}$ rises in the heavy ER clusters corresponds well with the multiple $\mathrm{Ca}^{2+}$ waves through the inner ER at egg activation and is somewhat analogous to that induced by the mouse sperm factor, a PLCל-induced $\mathrm{Ca}^{2+}$ mobilization by hydrolyzing internal phospholipid stores (Yu et al. 2012). The purified sperm factor shows high enzymatic activity for citrate synthase and the inhibition of its activity prevents egg activation not only by the sperm extract but also by the fertilizing sperm (Harada et al. 2011), indicating a central role for the enzymatic activity in the $\mathrm{Ca}^{2+}$ rises (Fig. 2B). Citrate synthase produces citrate from acetylCoA and oxaloacetate in the mitochondrial tricarboxylic acid (TCA) cycle but might inversely cleave the citrate, which is abundant in the egg cytoplasm, to produce acetyl-CoA and oxaloacetate (Srere 1992). Both acetyl$\mathrm{CoA}$ and oxaloacetate have sufficient activity to induce $\mathrm{Ca}^{2+}$ waves and egg activation in Cynops eggs, while citrate has not (Harada et al. 2011). It is reported that acetyl-CoA sensitizes the $I P_{3}$ receptors on the ER to induce $\mathrm{Ca}^{2+}$ releases (Missiaen et al. 1997) and that oxaloacetate induces the $\mathrm{Ca}^{2+}$ release from mitochondria (Leikin et al. 1993). As Cynops eggs are more sensitive to acetyl-CoA than to oxaloacetate, the acetylCoA associated with the sperm citrate synthase seems to be a major signal for the $\mathrm{Ca}^{2+}$ release from $\mathrm{IP}_{3}$ receptors on the ER at fertilization (Fig. 2B). However, the detailed mechanisms remain to be investigated. On the other hand, it is possible that sperm citrate synthase interacts with some other molecules involved in $\mathrm{Ca}^{2+}$ signaling in the egg cytoplasm. In this connection, the treatment of Cynops eggs with $\mathrm{D}_{2} \mathrm{O}$ enhances microtubule polymerization to form numerous small cytoasters in the egg cortex and causes egg activation (Iwao \& Masui 1995), suggesting at least some role for cytoskeletal filaments in the egg activation process. Interestingly, in the protozoa Tetrahymena, citrate synthase displays dual functions: as an active enzyme in mitochondria and as a cytoskeleton protein for $14 \mathrm{~nm}$ filaments (Numata et al. 1985, Numata 1996). The $14 \mathrm{~nm}$ filament protein, a dephosphorylated form of citrate synthase, is involved in oral morphogenesis and pronuclear behavior during fertilization (Numata et al. 1985, Kojima \& Numata 2002) and associated with the HSP60 protein (Takeda et al. 2001). Citrate synthase in newts may also play dual roles: as a mitochondrial enzyme and as a sperm factor for egg activation. Indeed, it is well known that some active enzymes, such as lactate dehydrogenase, have been recruited, unchanged, to an extra role as structural protein crystallins in the lens of the eye (Wistow et al. 1987, Tomarev \& Piatigorsky 1996).
We have also recently demonstrated that SGP on the sperm membrane has a bifunctional role in sperm binding to both the vitelline envelope and the egg plasma membrane at Xenopus fertilization (Nagai et al. 2009, Kubo et al. 2010). Further investigation of the function of citrate synthase, not only in fertilization but also in early embryonic development, will provide insight into $\mathrm{Ca}^{2+}$ signaling and cell cycle regulation.

\section{Specificity and variations in the sperm factor in vertebrates}

Egg activation by the Cynops sperm factor, citrate synthase, is specific for homologous eggs. Xenopus eggs are insensitive not only to the Cynops sperm factor but also to the homologous sperm extract without citrate synthase activity (Harada et al. 2011). These results indicating lack of $\mathrm{Ca}^{2+}$ release-inducing factor in Xenopus sperm cytoplasm supports the notion that the activation of Xenopus eggs is mediated by the membrane receptor. Xenopus sperm, however, contain a small amount of heat-stable activity to activate Cynops eggs, but which is quite different from that induced by citrate synthase. In this connection, it is reported that a Xenopus sperm extract contained a factor for triggering $\mathrm{Ca}^{2+}$ oscillations in mouse eggs (Dong et al. 2000) and that the injection of several Xenopus sperm into a homologous egg or a sperm-borne protein (PAWP) caused egg activation (Aarabi et al. 2010). The sperm of the monospermic frog, Bufo arenarum, contained two different types of activity, causing activation by injection into the egg or by external treatment (Bonilla et al. 2008). Further characterization of those factors will be necessary to clarify their roles in egg activation at frog fertilization.

The changes in $\left[\mathrm{Ca}^{2+}\right]_{i}$ have not been determined at polyspermy in other vertebrates, but an artificial increase in $\left[\mathrm{Ca}^{2+}\right]_{\mathrm{i}}$ in a bird blastodisc causes egg activation accompanied by pronucleus formation (Mizushima et al. 2007,2009 ). The injection of a sperm extract, but not of somatic cell extracts, induces egg activation dependent on intracellular $\mathrm{Ca}^{2+}$ activity (Mizushima et al. 2009). In addition, the injection of chicken sperm extract into mouse eggs induces $\mathrm{Ca}^{2+}$ rises and initiates embryo development (Dong et al. 2000, Kim \& Gye 2003). As bird PLC $\zeta$ causes activation in quail eggs (Mizushima et al. 2009) and triggers $\mathrm{Ca}^{2+}$ oscillations in mouse eggs (Coward et al. 2005), PLC $\zeta$ seems to be a potent sperm factor for egg activation in polyspermic birds, but further investigation for the factor like citrate synthase will be important.

\section{Perspectives in egg activation during evolution of vertebrates}

\section{A single $\mathrm{Ca}^{2+}$ rise in monospermy}

A review of the variations in egg activation systems, and particularly the $\mathrm{Ca}^{2+}$ rise at fertilization in living 
vertebrates (Fig. 3), may elucidate the evolutionary history of egg activation concomitant with the acquisition of polyspermy. In vertebrates, most fishes exhibit monospermy, except for cartilaginous fishes (elasmobranchs) such as sharks and chimaera (Hart 1990). In the primitive jawless fishes (Agnathans), the lampreys exhibit monospermy with a positive-going fertilization potential mediated by $\mathrm{Ca}^{2+}$-activated $\mathrm{Cl}^{-}$channels (Kobayashi et al. 1994). The pattern of fertilization potential alike in anuran eggs indicates a transient $\mathrm{Ca}^{2+}$ rise at lamprey fertilization. In the bony fish (Teleosts), Medaka (Oryzias latipes), a transient $\mathrm{Ca}^{2+}$ wave is induced by a fertilizing sperm from its entry site (Gilkey et al. 1978). In frogs, monospermy is ensured by a positive-going fertilization potential mediated by the propagative opening of $\mathrm{Ca}^{2+}$-activated $\mathrm{Cl}^{-}$channels (Kline \& Nuccitelli 1985) preceded by a transient $\mathrm{Ca}^{2+}$ wave. In monospermic salamanders (urodeles), Hynobius eggs open $\mathrm{Ca}^{2+}$-activated $\mathrm{Cl}^{-}$channels to produce a positive-going fertilization potential (Iwao 1989), indicating a transient $\mathrm{Ca}^{2+}$ wave at egg activation. Thus, the transient and large $\mathrm{Ca}^{2+}$ wave induced by a single sperm entry is probably characteristic of monospermic eggs in vertebrates, implying that the ancestor of vertebrates exhibited monospermy with a single and long-lasting $\mathrm{Ca}^{2+}$ wave.

\section{Multiple $\mathrm{Ca}^{2+}$ rises in polyspermy}

In anamniotes, multiple $\mathrm{Ca}^{2+}$ waves (rises) are required for egg activation in the polyspermic eggs of physiological polyspermic Cynops (urodeles). Multiple $\mathrm{Ca}^{2+}$ rises appear to occur in occasionally polyspermic eggs of the frog Discoglossus (anurans). The multiple $\mathrm{Ca}^{2+}$ waves caused by a sperm cytosolic factor, e.g. citrate synthase, may reflect an evolutionary adaptation related to a change in mode of fertilization, e.g. the acquisition of physiological polyspermy. The close relationships in the acquisition of polyspermy between internal fertilization, increased egg size, centrosome dynamics, etc. have been the subject of much discussion (Elinson 1986, Wong \& Wessel 2006, Snook et al. 2011). Physiological polyspermy might arise in large eggs with external fertilization, as in the Japanese giant salamander, Andrias japonicus, the large eggs $(5-8 \mathrm{~mm}$ in diameter) inseminated after oviposition undergo polyspermic fertilization (Iwao 2000a). The extra space in the egg cytoplasm of large eggs is one of the most important factors for eliminating accessory sperm nuclei in the same egg cytoplasm, according to the 'large egg model' (Elinson 1986). Although physiological polyspermy is required to ensure fertilization in large eggs (Harper 1904), a single sperm does not contain sufficient sperm factor to induce the $\mathrm{Ca}^{2+}$ rise required for activation in a large egg. Multiple $\mathrm{Ca}^{2+}$ rises appear to be necessary for complete activation of large eggs. It has been hypothesized that the cytological polyspermy block in physiological polyspermy represents a more ancient type (Wong \& Wessel 2006) and that urodeles and anurans may have arisen from different origins (Elinson 1986). As monospermic anurans may have branched from

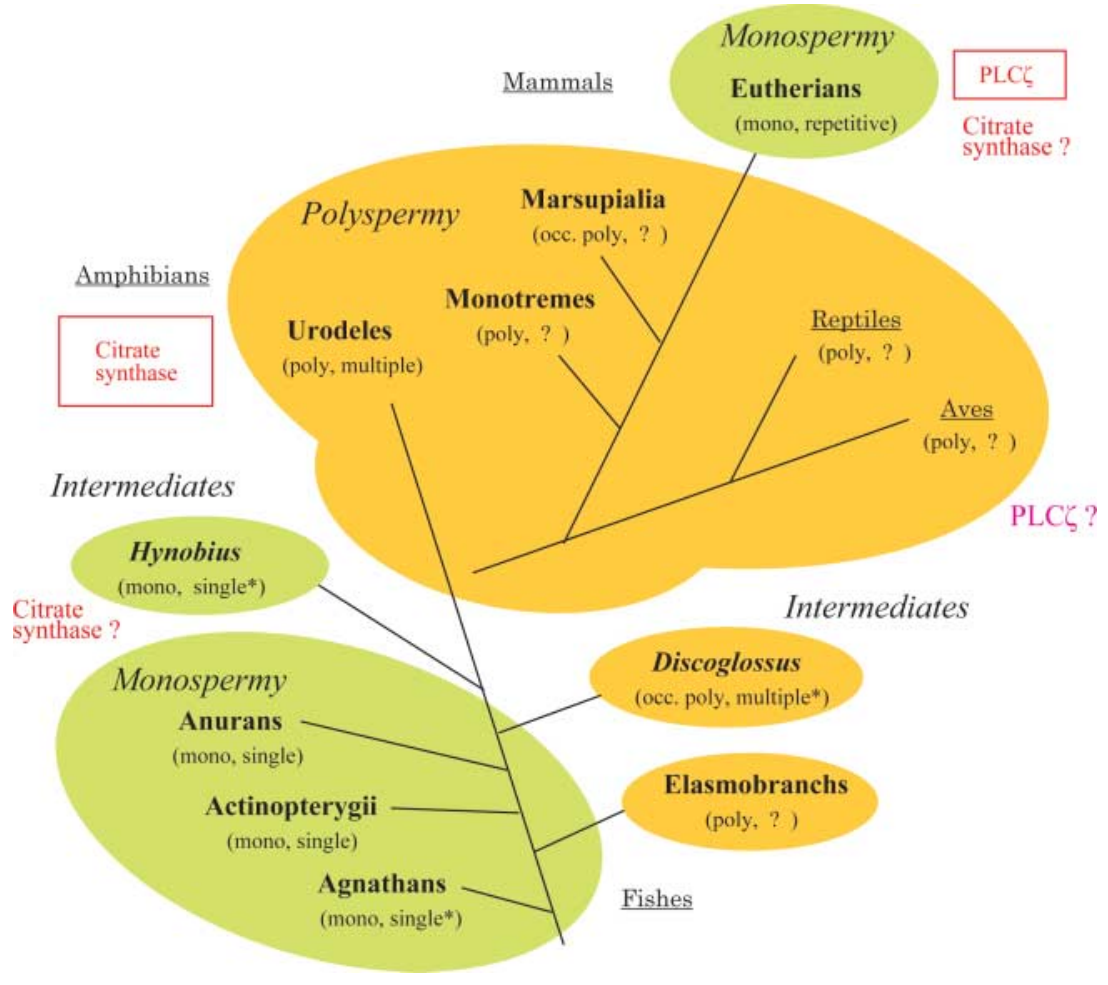

Figure 3 Variations in the mode of fertilization and $\mathrm{Ca}^{2+}$ rises in egg activation among vertebrates. poly, polyspermy; occ. poly, occasional polyspermy; mono, monospermy; single, a single $\mathrm{Ca}^{2+}$ rise at egg activation; multiple, multiple $\mathrm{Ca}^{2+}$ rises at egg activation; ${ }^{*} \mathrm{Ca}^{2+}$ rises presumed due to opening of $\mathrm{Ca}^{2+}$-activated $\mathrm{Cl}^{-}$channels. 
urodeles during the beginning of the Mesozoic period (240 million years ago; Feller \& Hedges 1998), around the period when the ancestor of mammals appeared, multiple $\mathrm{Ca}^{2+}$ rises capable of activating large polyspermic eggs might be a characteristic shared with species that possess polyspermic amniotic eggs. It will be important to determine whether multiple $\mathrm{Ca}^{2+}$ rises occur at physiological polyspermy in living amniotes, reptiles, and birds.

\section{$\mathrm{Ca}^{2+}$ oscillations in monospermic mammals}

Higher eutherian mammals, however, exhibit monospermy and their sperm-specific PLC $\zeta$ induce repetitive $\mathrm{Ca}^{2+}$ rises (oscillations) at egg activation (Fig. 1C and F; Swann et al. 2006, Nomikos et al. 2012). The fertilization of primitive mammals can be very instructive. The monotrematous platypus, Ornithorhynchus anatinus, lays large yolky eggs (about $4 \mathrm{~mm}$ in diameter) that undergo meroblastic cleavage in blastodiscs (Hughes \& Hall 1998). The platypus eggs are polyspermic and several sperm probably enter into a blastodisc $(41 \times 368 \mu \mathrm{m}$; Gatenby \& Hill 1924). In the small marsupial mammal, Sminthopsis crassicaudata, the relatively small egg (about $120 \mu \mathrm{m}$ in diameter) contained a yolk mass in the center and some eggs are polyspermic (Breed \& Leigh 1990). Thus, the decrease in egg size and yolk content is closely associated with the change in the mode of fertilization, from polyspermy to monospermy, in mammals. Although the changes in $\left[\mathrm{Ca}^{2+}\right]_{i}$ at fertilization have not been reported in those primitive mammals, it may be that the ancestor of mammals exhibited polyspermy, which is required for repetitive $\mathrm{Ca}^{2+}$ waves and the induction of egg activation. Higher eutherians have small eggs (about $100 \mu \mathrm{m}$ in diameter) without a yolk in the egg cytoplasm, but multiple $\mathrm{Ca}^{2+}$ rises lasting more than $1 \mathrm{~h}$ are still necessary for complete activation of mouse eggs (Ozil 1990, Ducibella et al. 2002), indicating that the first $\mathrm{Ca}^{2+}$ rise by the entry of a single sperm is insufficient for egg activation. It may be the case that $\mathrm{Ca}^{2+}$ oscillations in the relatively small eutherian eggs might be functioning in place of multiple $\mathrm{Ca}^{2+}$ waves of the ancestral polyspermic eggs. It should be, however, mentioned that the monospermic eggs in invertebrates exhibit $\mathrm{Ca}^{2+}$ oscillations during fertilization (Stricker 1999, Dumollard et al. 2002) and multiple $\mathrm{Ca}^{2+}$ rises might be associated with longer period in completion of meiosis after fertilization.

\section{Conclusions}

We have described the mechanism of the induction of multiple $\mathrm{Ca}^{2+}$ waves required for egg activation in polyspermic eggs. The review of the variations in the $\mathrm{Ca}^{2+}$ rise at egg activation among vertebrates suggests the $\mathrm{Ca}^{2+}$ rise concomitant with the transition in the mode of fertilization between monospermy and polyspermy. The sperm cytosolic factors for egg activation may have played a role in the evolution of slower activation in polyspermic eggs and may promote the reproductive isolation necessary for speciation in vertebrates. Interestingly, mouse sperm having the potent sperm factor PLC $\zeta$, as well as sperm of the monospermic salamander, Hynobius, contain a large amount of citrate synthase outside the mitochondria (Iwao \& Harada 2011, unpublished observations). As reliable fertilization mechanisms are indispensable for sexual reproduction, any abrupt change in egg activation, such as that induced by an alternative sperm factor, would not likely be selected for during evolution. As some species among vertebrates may still possess intermediate characteristics of these sperm factors, future research should attempt to clarify the role of citrate synthase in egg activation of amniotic vertebrates. A comprehensive phylogenetic analysis of the sperm factors for egg activation will help to elucidate their roles in vertebrate evolution and may uncover previously overlooked mechanisms in reproductive and early developmental systems.

\section{Declaration of interest}

The authors declare that there is no conflict of interest that could be perceived as prejudicing the impartiality of the review reported.

\section{Funding}

This work was supported in part by a grant-in-aid for scientific research on innovative areas from MEXT (22112518, 24112712).

\section{Acknowledgements}

The authors dedicate this paper to late Prof. Chiaki Katagiri for his valuable advice and words of encouragement over the years. They also thank Yuichrou Harada and Shuichi Ueno for critical reading of the manuscript and Tomoyo Ueno for her help on preparing the manuscript.

\section{References}

Aarabi M, Qin Z, Xu W, Mewburn J \& Oko R 2010 Sperm-borne protein, PAWP, initiates zygotic development in Xenopus laevis by eliciting intracellular calcium release. Molecular Reproduction and Development $77249-256$.

Aimar C \& Labrousse J-P 1975 DNA synthesis and evolution, in presence of a somatic nucleus, of the female pronucleus after experimental activation of the egg of Pleurodeles waltlii. Development, Growth \& Differentiation 17 197-207. (doi:10.1111/j.1440-169X.1975.00197.x)

Bonilla F, Ajmat MT, Sanchez Toranzo G, Zelarayan L, Oterino J \& Buhler MI 2008 Activation of amphibian oocytes by sperm extracts. Zygote 16 303-308. (doi:10.1017/S0967199408004814) 
Breed WG \& Leigh CM 1990 Morphological changes in the oocyte and its surrounding vestments during in vivo fertilization in the dasyurid marsupial Sminthopsis crassicaudata. Journal of Morphology 204 177-196. (doi:10.1002/jmor.1052040207)

Carré D \& Sardet C 1984 Fertilization and early development in Beroe ovata. Developmental Biology 105 188-195. (doi:10.1016/0012-1606 (84)90274-4)

Charbonneau M \& Picheral B 1983 Early events in anuran amphibian fertilization: an ultrastructural study of changes occurring in the course of monospermic fertilization and artificial activation. Development, Growth \& Differentiation 25 23-37. (doi:10.1111/j.1440-169X.1983. 00023.x)

Charbonneau M, Moreau M, Picheral B, Vilain JP \& Guerrier P 1983 Fertilization of amphibian eggs: a comparison of electrical responses between anurans and urodeles. Developmental Biology 98 304-318. (doi:10.1016/0012-1606(83)90361-5)

Coward K, Campos-Mendoza A, Larman M, Hibbitt O, McAndrew B, Bromage N \& Parrington J 2003 Teleost fish spermatozoa contain a cytosolic protein factor that induces calcium release in sea urchin egg homogenates and triggers calcium oscillations when injected into mouse oocytes. Biochemical and Biophysical Research Communications 305 299-304. (doi:10.1016/S0006-291X(03)00753-8)

Coward K, Ponting CP, Chang HY, Hibbitt O, Savolainen P, Jones KT \& Parrington J 2005 Phospholipase $\mathrm{C}_{\boldsymbol{\zeta}}$, the trigger of egg activation in mammals, is present in a non-mammalian species. Reproduction 130 157-163. (doi:10.1530/rep.1.00707)

Coward K, Ponting CP, Zhang N, Young C, Huang CJ, Chou CM, Kashir J, Fissore RA \& Parrington J 2011 Identification and functional analysis of an ovarian form of the egg activation factor phospholipase $\mathrm{C} \zeta$ (PLC $\zeta$ ) in pufferfish. Molecular Reproduction and Development 78 48-56. (doi:10.1002/mrd.21262)

Cross NL \& Elinson RP 1980 A fast block to polyspermy in frogs mediated by changes in the membrane potential. Developmental Biology $\mathbf{7 5}$ 187-198. (doi:10.1016/0012-1606(80)90154-2)

Dong JB, Tang TS \& Sun FZ 2000 Xenopus and chicken sperm contain a cytosolic soluble protein factor which can trigger calcium oscillations in mouse eggs. Biochemical and Biophysical Research Communications 268 947-951. (doi:10.1006/bbrc.2000.2218)

Ducibella T, Huneau D, Angelichio E, Xu Z, Schultz RM, Kopf GS, Fissore R, Madoux S \& Ozil JP 2002 Egg-to-embryo transition is driven by differential responses to $\mathrm{Ca}^{2+}$ oscillation number. Developmental Biology 250 280-291. (doi:10.1006/dbio.2002.0788)

Dumollard R, Carroll J, Dupont G \& Sardet C 2002 Calcium wave pacemakers in eggs. Journal of Cell Science 115 3557-3564. (doi:10. 1242/jcs.00056)

Elinson RP 1986 Fertilization in amphibians: the ancestry of the block to polyspermy. International Review of Cytology 101 59-100.

Fankhauser G 1948 The organization of the amphibian egg during fertilization and cleavage. Annals of the New York Academy of Sciences 49 684-708. (doi:10.1111/j.1749-6632.1948.tb30961.x)

Feller AE \& Hedges SB 1998 Molecular evidence for the early history of living amphibians. Molecular Phylogenetics and Evolution 9 509-516. (doi:10.1006/mpev.1998.0500)

Fontanilla RA \& Nuccitelli R 1998 Characterization of the sperm-induced calcium wave in Xenopus eggs using confocal microscopy. Biophysical Journal 75 2079-2087. (doi:10.1016/S0006-3495(98)77650-7)

Gardner AJ, Williams CJ \& Evans JP 2007 Establishment of the mammalian membrane block to polyspermy: evidence for calcium-dependent and -independent regulation. Reproduction 133 383-393. (doi:10.1530/ REP-06-0304)

Gatenby JB \& Hill JP 1924 On an ovum of Ornithorhynchus exhibiting polar bodies and polyspermy. Journal of Cell Science s2-68 229-238.

Gianaroli L, Tosti E, Magli C, laccarino M, Ferraretti AP \& Dale B 1994 Fertilization current in the human oocyte. Molecular Reproduction and Development 38 209-214. (doi:10.1002/mrd.1080380212)

Gilkey JC, Jaffe LF, Ridgway EB \& Reynolds GT 1978 A free calcium wave traverses the activating egg of the medaka, Oryzias latipes. Journal of Cell Biology 76 448-466. (doi:10.1083/jcb.76.2.448)

Goudeau M \& Goudeau H 1993 Successive electrical responses to insemination and concurrent sperm entries in the polyspermic egg of the ctenophore Beroe ovata. Developmental Biology 156 537-551. (doi:10.1006/dbio.1993.1100)
Grandin N \& Charbonneau M 1992 Intracellular free $\mathrm{Ca}^{2+}$ changes during physiological polyspermy in amphibian eggs. Development 114 617-624.

Harada Y, Matsumoto T, Hirahara S, Nakashima A, Ueno S, Oda S, Miyazaki S \& Iwao Y 2007 Characterization of a sperm factor for egg activation at fertilization of the newt Cynops pyrrhogaster. Developmental Biology 306 797-808. (doi:10.1016/j.ydbio.2007.04.019)

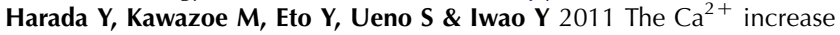
by the sperm factor in physiologically polyspermic newt fertilization: its signaling mechanism in egg cytoplasm and the species-specificity. Developmental Biology 351 266-276. (doi:10.1016/j.ydbio.2011. 01.003)

Harper EH 1904 The fertilization and early development of the pigeon's egg. American Journal of Anatomy 3 349-386. (doi:10.1002/aja. 1000030402)

Hart NH 1990 Fertilization in teleost fishes: mechanisms of sperm-egg interactions. International Review of Cytology 121 1-66.

Hedrick JL 2008 Anuran and pig egg zona pellucida glycoproteins in fertilization and early development. International Journal of Developmental Biology 52 683-701. (doi:10.1387/ijdb.082580jh)

Houliston E, Carre D, Johnston JA \& Sardet C 1993 Axis establishment and microtubule-mediated waves prior to first cleavage in Beroe ovata. Development 117 75-87.

Hughes RL \& Hall LS 1998 Early development and embryology of the platypus. Philosophical Transactions of the Royal Society of London. Series B, Biological sciences 353 1101-1114. (doi:10.1098/rstb.1998. 0269)

Iwamatsu T 2000 Fertilization in fishes. In Fertilization in Protozoa and Metazoan Animal, pp 89-146. Eds JJ Tarín\& A Cano. Berlin: Springer.

Iwamatsu T \& Ohta I 1974 Cleavage initiating activities of sperm fractions injected into the egg of the medaka, Oryzias latipes. Journal of Experimental Zoology 187 3-15. (doi:10.1002/jez.1401870103)

Iwao Y 1985 The membrane potential changes of amphibian eggs during species- and cross-fertilization. Developmental Biology $11126-34$. (doi:10.1016/0012-1606(85)90431-2)

Iwao Y 1989 An electrically mediated block to polyspermy in the primitive urodele Hynobius nebulosus and phylogenetic comparison with other amphibians. Developmental Biology 134 438-445. (doi:10.1016/00121606(89)90116-4)

Iwao Y 2000a Fertilization in amphibians. In Fertilization in Protozoa and Metazoan Animal, pp 147-191. Eds JJ Tarín\& A Cano. Berlin: Springer.

Iwao Y $2000 b$ Mechanisms of egg activation and polyspermy block in amphibians and comparative aspects with fertilization in other vertebrates. Zoological Science 17 699-709. (doi:10.2108/zsj.17.699)

Iwao Y \& Jaffe LA 1989 Evidence that the voltage-dependent component in the fertilization process is contributed by the sperm. Developmental Biology 134 446-451. (doi:10.1016/0012-1606(89)90117-6)

Iwao Y \& Elinson RP 1990 Control of sperm nuclear behavior in physiologically polyspermic newt eggs: possible involvement of MPF. Developmental Biology 142 301-312. (doi:10.1016/0012-1606(90) 90351-I)

Iwao Y \& Masui Y 1995 Activation of newt eggs in the absence of $\mathrm{Ca}^{2+}$ activity by treatment with cycloheximide or $\mathrm{D}_{2} \mathrm{O}$. Development, Growth \& Differentiation 37 641-651. (doi:10.1046/j.1440-169X.1995.t01-500003.x)

Iwao Y \& Fujimura T 1996 Activation of Xenopus eggs by RGD-containing peptides accompanied by intracellular $\mathrm{Ca}^{2+}$ release. Developmental Biology 177 558-567. (doi:10.1006/dbio.1996.0185)

Iwao Y, Yamasaki H \& Katagiri C 1985 Experiments pertaining to the suppression of accessory sperm in fertilized newt eggs. Development, Growth \& Differentiation 27 323-331. (doi:10.1111/j.1440-169X.1985. 00323.x)

Iwao Y, Sakamoto N, Takahara K, Yamashita M \& Nagahama Y 1993 The egg nucleus regulates the behavior of sperm nuclei as well as cycling of MPF in physiologically polyspermic newt eggs. Developmental Biology 160 15-27. (doi:10.1006/dbio.1993.1282)

Iwao Y, Miki A, Kobayashi M \& Onitake K 1994 Activation of Xenopus eggs by an extract of Cynops sperm. Development, Growth \& Differentiation 36 469-479. (doi:10.1111/j.1440-169X.1994.00469.x)

Iwao Y, Yasumitsu K, Narihira M, Jiang J \& Nagahama Y 1997 Changes in microtubule structures during the first cell cycle of physiologically 
polyspermic newt eggs. Molecular Reproduction and Development 47 210-221. (doi:10.1002/(SICl)1098-2795(199706)47:2 <210::AID-MRD $13>3.0 . \mathrm{CO} ; 2-3)$

Iwao Y, Murakawa T, Yamaguchi J \& Yamashita M 2002 Localization of $\gamma$-tubulin and cyclin B during early cleavage in physiologically polyspermic newt eggs. Development, Growth \& Differentiation 44 489-499. (doi:10.1046/j.1440-169X.2002.00661.x)

Jaffe LA, Sharp AP \& Wolf DP 1983 Absence of an electrical polyspermy block in the mouse. Developmental Biology 96 317-323. (doi:10.1016/ 0012-1606(83)90168-9)

Kim ST \& Gye MC 2003 Activation of mouse oocytes following intracytoplasmic injection of chicken sperm extract. Reproduction in Domestic Animals 38 401-404. (doi:10.1046/j.1439-0531.2003. 00455.x)

Kline D \& Nuccitelli R 1985 The wave of activation current in the Xenopus egg. Developmental Biology 111 471-487. (doi:10.1016/0012-1606 (85)90499-3)

Kline D \& Stewart-Savage J 1994 The timing of cortical granule fusion, content dispersal, and endocytosis during fertilization of the hamster egg: an electrophysiological and histochemical study. Developmental Biology 162 277-287. (doi:10.1006/dbio.1994.1085)

Kobayashi W, Baba Y, Shimozawa T \& Yamamoto TS 1994 The fertilization potential provides a fast block to polyspermy in lamprey eggs. Developmental Biology 161 552-562. (doi:10.1006/dbio.1994.1053)

Kojima H \& Numata O 2002 Enzymatic form and cytoskeletal form of bifunctional Tetrahymena $49 \mathrm{kDa}$ protein is regulated by phosphorylation. Zoological Science 19 37-42. (doi:10.2108/zsj.19.37)

Kouchi Z, Fukami K, Shikano T, Oda S, Nakamura Y, Takenawa T \&

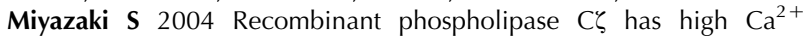
sensitivity and induces $\mathrm{Ca}^{2+}$ oscillations in mouse eggs. Journal of Biological Chemistry 279 10408-10412. (doi:10.1074/jbc.M313 801200)

Kubo H, Shiga K, Harada Y \& Iwao Y 2010 Analysis of a sperm surface molecule that binds to a vitelline envelope component of Xenopus laevis eggs. Molecular Reproduction and Development 77 728-735. (doi:10.1002/mrd.21211)

Leikin YN, Zharova TV \& Tjulina OV 1993 Novel oxaloacetate effect on mitochondrial $\mathrm{Ca}^{2+}$ movement. FEBS Letters 331 35-37. (doi:10.1016/ 0014-5793(93)80292-3)

Mahbub Hasan AK, Sato K, Sakakibara K, Ou Z, Iwasaki T, Ueda Y \& Fukami Y 2005 Uroplakin III, a novel Src substrate in Xenopus egg rafts, is a target for sperm protease essential for fertilization. Developmental Biology 286 483-492. (doi:10.1016/j.ydbio.2005.08.020)

Mahbub Hasan AK, Ou Z, Sakakibara K, Hirahara S, Iwasaki T, Sato K \& Fukami Y 2007 Characterization of Xenopus egg membrane microdomains containing uroplakin Ib/III complex: roles of their molecular interactions for subcellular localization and signal transduction. Genes to Cells 12 251-267. (doi:10.1111/j.1365-2443.2007.01048.x)

Missiaen L, Parys JB, Smedt HD, Sienaert I, Sipma H, Vanlingen S, Maes K \& Casteels R 1997 Effect of adenine nucleotides on myo-inositol-1,4, 5-trisphosphate-induced calcium release. Biochemical Journal 325 ( $\mathrm{Pt} \mathrm{3}$ ) 661-666.

Mizote A, Okamoto S \& Iwao Y 1999 Activation of Xenopus eggs by proteases: possible involvement of a sperm protease in fertilization. Developmental Biology 208 79-92. (doi:10.1006/dbio.1999.9195)

Mizushima S, Takagi S, Ono T, Atsumi Y, Tsukada A, Saito N \& Shimada K 2007 Possible role of calcium on oocyte development after intracytoplasmic sperm injection in quail (Coturnix japonica). Journal of Experimental Zoology. Part A, Ecological Genetics and Physiology 307 647-653. (doi:10.1002/jez.a.418)

Mizushima S, Takagi S, Ono T, Atsumi Y, Tsukada A, Saito N \& Shimada K

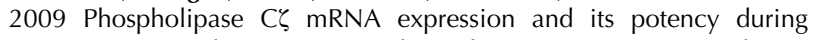
spermatogenesis for activation of quail oocyte as a sperm factor. Molecular Reproduction and Development 76 1200-1207. (doi:10. 1002/mrd.21097)

Nagai K, Ishida T, Hashimoto T, Harada Y, Ueno S, Ueda Y, Kubo H \& Iwao Y 2009 The sperm-surface glycoprotein, SGP, is necessary for fertilization in the frog, Xenopus laevis. Development, Growth \& Differentiation 51 499-510. (doi:10.1111/j.1440-169X.2009.01112.x)

Nishiyama T, Yoshizaki N, Kishimoto T \& Ohsumi K 2007 Transient activation of calcineurin is essential to initiate embryonic development in Xenopus laevis. Nature 449 341-345. (doi:10.1038/nature06136)
Nomikos M, Swann K \& Lai FA 2012 Starting a new life: sperm PLC-zeta mobilizes the $\mathrm{Ca}^{2+}$ signal that induces egg activation and embryo development: an essential phospholipase $C$ with implications for male infertility. BioEssays: News and Reviews in Molecular, Cellular and Developmental Biology 34 126-134. (doi:10.1002/bies.201100127)

Nuccitelli R 1980 The fertilization potential is not necessary for the block to polyspermy or the activation of development in the medaka egg. Developmental Biology 76 499-504. (doi:10.1016/0012-1606(80) 90397-8)

Nuccitelli R, Kline D, Busa WB, Talevi R \& Campanella C 1988 A highly localized activation current yet widespread intracellular calcium increase in the egg of the frog, Discoglossus pictus. Developmental Biology 130 120-132. (doi:10.1016/0012-1606(88)90419-8)

Nuccitelli R, Yim DL \& Smart T 1993 The sperm-induced $\mathrm{Ca}^{2+}$ wave following fertilization of the Xenopus egg requires the production of Ins(1, 4, 5)P3. Developmental Biology 158 200-212. (doi:10.1006/dbio. 1993.1179)

Numata O 1996 Multifunctional proteins in Tetrahymena: 14-nm filament protein/citrate synthase and translation elongation factor-1 alpha. International Review of Cytology 164 1-35. (doi:10.1016/S00747696(08)62383-9)

Numata O, Sugai T \& Watanabe Y 1985 Control of germ cell nuclear behaviour at fertilization by Tetrahymena intermediate filament protein. Nature 314 192-194. (doi:10.1038/314192a0)

Oda S, Deguchi R, Mohri T, Shikano T, Nakanishi S \& Miyazaki S 1999 Spatiotemporal dynamics of the $\left[\mathrm{Ca}^{2+}\right]_{i}$ rise induced by microinjection of sperm extract into mouse eggs: preferential induction of $\mathrm{a} \mathrm{Ca}^{2+}$ wave from the cortex mediated by the inositol 1,4,5-trisphosphate receptor. Developmental Biology 209 172-185. (doi:10.1006/dbio.1999.9233)

Ozil JP 1990 The parthenogenetic development of rabbit oocytes after repetitive pulsatile electrical stimulation. Development 109 117-127.

Parrington J, Swann K, Shevchenko VI, Sesay AK \& Lai FA 1996 Calcium oscillations in mammalian eggs triggered by a soluble sperm protein. Nature 379 364-368. (doi:10.1038/379364a0)

Pelczar H, Caulet S, Thibier C, Aubet G, Poulhe R, Vallianou I, Yamashita M \& Andeol Y 2007 Characterization and expression of a maternal axolotl cyclin B1 during oogenesis and early development. Development, Growth \& Differentiation 49 407-419. (doi:10.1111/j. 1440-169X.2007.00934.x)

Perry MM 1987 Nuclear events from fertilisation to the early cleavage stages in the domestic fowl (Gallus domesticus). Journal of Anatomy $\mathbf{1 5 0}$ 99-109.

Picheral B 1977 La fecondation chez le triton pleurodele. II. La penetration des spermatozoides et la reaction locale de l'oeuf. Journal of Ultrastructure Research 60 181-202. (doi:10.1016/S0022-5320(77)80064-6)

Rouvière C, Houliston E, Carré D, Chang P \& Sardet C 1994 Characteristics of pronuclear migration in Beroe ovata. Cell Motility and the Cytoskeleton 29 301-311. (doi:10.1002/cm.970290403)

Sakakibara K, Sato K, Yoshino K, Oshiro N, Hirahara S, Mahbub Hasan AK, Iwasaki T, Ueda Y, Iwao Y, Yonezawa K et al. 2005 Molecular identification and characterization of Xenopus egg uroplakin III, an egg raft-associated transmembrane protein that is tyrosine-phosphorylated upon fertilization. Journal of Biological Chemistry 280 15029-15037. (doi:10.1074/jbc.M410538200)

Sakamoto I, Takahara K, Yamashita M \& Iwao Y 1998 Changes in cyclin B during oocyte maturation and early embryonic cell cycle in the newt, Cynops pyrrhogaster: requirement of germinal vesicle for MPF activation. Developmental Biology 195 60-69. (doi:10.1006/dbio.1997.8835)

Sato K, Iwao Y, Fujimura T, Tamaki I, Ogawa K, Iwasaki T, Tokmakov AA, Hatano O \& Fukami Y 1999 Evidence for the involvement of a Srcrelated tyrosine kinase in Xenopus egg activation. Developmental Biology 209 308-320. (doi:10.1006/dbio.1999.9255)

Sato K, Tokmakov AA, He CL, Kurokawa M, Iwasaki T, Shirouzu M, Fissore RA, Yokoyama S \& Fukami Y 2003 Reconstitution of Srcdependent phospholipase $C_{\gamma}$ phosphorylation and transient calcium release by using membrane rafts and cell-free extracts from Xenopus eggs. Journal of Biological Chemistry 278 38413-38420. (doi:10.1074/ jbc.M302617200)

Saunders CM, Larman MG, Parrington J, Cox LJ, Royse J, Blayney LM, Swann K \& Lai FA 2002 PLC $\zeta$ : a sperm-specific trigger of $\mathrm{Ca}^{2+}$ oscillations in eggs and embryo development. Development 129 3533-3544. 
Shilling FM, Magie CR \& Nuccitelli R 1998 Voltage-dependent activation of frog eggs by a sperm surface disintegrin peptide. Developmental Biology 202 113-124. (doi:10.1006/dbio.1998.8982)

Snook RR, Hosken DJ \& Karr TL 2011 The biology and evolution of polyspermy: insights from cellular and functional studies of sperm and centrosomal behavior in the fertilized egg. Reproduction 142 779-792. (doi:10.1530/REP-11-0255)

Srere PA 1992 The molecular physiology of citrate. Current Topics in Cellular Regulation 33 261-275.

Stricker SA 1999 Comparative biology of calcium signaling during fertilization and egg activation in animals. Developmental Biology 211 157-176. (doi:10.1006/dbio.1999.9340)

Swann K 1990 A cytosolic sperm factor stimulates repetitive calcium increases and mimics fertilization in hamster eggs. Development $\mathbf{1 1 0}$ 1295-1302.

Swann K, Saunders CM, Rogers NT \& Lai FA 2006 PLC $\zeta$ (zeta): a sperm protein that triggers $\mathrm{Ca}^{2+}$ oscillations and egg activation in mammals. Seminars in Cell \& Developmental Biology 17 264-273. (doi:10.1016/j. semcdb.2006.03.009)

Takeda T, Yoshihama I \& Numata O 2001 Identification of Tetrahymena hsp60 as a 14-nm filament protein/citrate synthase-binding protein and its possible involvement in the oral apparatus formation. Genes to Cells 6 139-149. (doi:10.1046/j.1365-2443.2001.00400.x)

Talevi R 1989 Polyspermic eggs in the anuran Discoglossus pictus develop normally. Development 105 343-349.

Talevi R \& Campanella C 1988 Fertilization in Discoglossus pictus (Anura). I. Sperm-egg interactions in distinct regions of the dimple and occurrence of a late stage of sperm penetration. Developmental Biology 130 524-535. (doi:10.1016/0012-1606(88)90347-8)

Talevi R, Dale B \& Campanella C 1985 Fertilization and activation potentials in Discoglossus pictus (Anura) eggs: a delayed response to activation by pricking. Developmental Biology 111 316-323. (doi:10. 1016/0012-1606(85)90486-5)

Tomarev SI \& Piatigorsky J 1996 Lens crystallins of invertebrates - diversity and recruitment from detoxification enzymes and novel proteins. European Journal of Biochemistry 235 449-465. (doi:10.1111/j.14321033.1996.00449.x)

Vaur S, Poulhe R, Maton G, Andeol Y \& Jessus C 2004 Activation of Cdc2 kinase during meiotic maturation of axolotl oocyte. Developmental Biology 267 265-278. (doi:10.1016/j.ydbio.2003.12.002)
Waddington D, Gribbin C, Sterling RJ, Sang HM \& Perry MM 1998 Chronology of events in the first cell cycle of the polyspermic egg of the domestic fowl (Gallus domesticus). International Journal of Developmental Biology 42 625-628.

Wakimoto BT 1979 DNA synthesis after polyspermic fertilization in the axolotl. Journal of Embryology and Experimental Morphology 52 39-48.

Whitaker M 2006 Calcium at fertilization and in early development. Physiological Reviews 86 25-88. (doi:10.1152/physrev.00023.2005)

Wistow GJ, Mulders JW \& de Jong WW 1987 The enzyme lactate dehydrogenase as a structural protein in avian and crocodilian lenses. Nature 326 622-624. (doi:10.1038/326622a0)

Wong JL \& Wessel GM 2006 Defending the zygote: search for the ancestral animal block to polyspermy. Current Topics in Developmental Biology 72 1-151.

Yamamoto S, Yamashita M \& Iwao Y 1999 Rise of intracellular $\mathrm{Ca}^{2+}$ level causes the decrease of cyclin B1 and Mos in the newt eggs at fertilization. Molecular Reproduction and Development 53 341-349. (doi:10.1002/ (SICI)1098-2795(199907)53:3<341::AID-MRD10>3.0.CO;2-E)

Yamamoto S, Kubota HY, Yoshimoto Y \& Iwao Y 2001 Injection of a sperm extract triggers egg activation in the newt Cynops pyrrhogaster. Developmental Biology 230 89-99. (doi:10.1006/dbio.2000.9949)

Yoda A, Oda S, Shikano T, Kouchi Z, Awaji T, Shirakawa H, Kinoshita K \& Miyazaki S $2004 \mathrm{Ca}^{2+}$ oscillation-inducing phospholipase C zeta expressed in mouse eggs is accumulated to the pronucleus during egg activation. Developmental Biology 268 245-257. (doi:10.1016/j.ydbio. 2003.12.028)

Yoshimoto Y \& Hiramoto Y 1991 Observation of intracellular $\mathrm{Ca}^{2+}$ with aequorin luminescence. International Review of Cytology 129 45-73.

Yu Y, Nomikos M, Theodoridou M, Nounesis G, Lai FA \& Swann K 2012 PLC $\zeta$ causes $\mathrm{Ca}^{2+}$ oscillations in mouse eggs by targeting intracellular and not plasma membrane PI(4,5)P2. Molecular Biology of the Cell 23 371-380. (doi:10.1091/mbc.E11-08-0687)

Received 23 March 2012

First decision 23 April 2012

Accepted 23 May 2012 